\title{
Garcinia macrophylla e Clusia grandiflora (CLUSIACEAE LINDL.): ensaios antioxidantes e georreferenciamento na Estação Ecológica do Jari
}

\author{
Garcinia macrophylla e Clusia grandiflora (CLUSIACEAE LINDL.): antioxidant assays and \\ georeferencing at the Jari Ecological Station \\ Wilson Bruno Conceição Fernandes' \\ Luan Patrick dos Santos Silva" \\ Haroldo da Silva Ripardo Filho"'I
}

\section{Resumo}

As plantas são uma excelente fonte de metabólitos secundários detentores de atividade biológica. Esses produtos naturais tem potencial para serem empregados em diferentes setores da indústria, como a de alimentos, agroquímica, farmacêutica, de cosméticas e perfumaria. Dentre as atividades apresentadas pelos metabólitos secundários de plantas, encontra-se a antioxidante, compostos com essas características são procurados pelas indústrias de alimentos e farmacêutica, para produção de conservantes, suplementos alimentares e medicamentos. Com base no pressuposto acima, o presente trabalho teve como objetivo avaliar a atividade antioxidante de espécies da família Clusiaceae, encontradas na Estação Ecológica do Jari, assim como georreferenciar essas espécies dentro da Área de Proteção Permanente. As espécies envolvidas nesse estudo foram a Garcinia macrophilla, popularmente conhecida como bacuripari e Clusia grandiflora, que possui o nome popular de cebola "braba". Os ensaios antioxidantes foram realizados com o extrato etanólico das raízes das duas plantas, pela técnica de bioautografia. Os resultados dos ensaios, atestaram que os extratos de ambas espécies são ativos e que possuem várias substâncias antioxidantes em sua composição. Com relação ao georreferenciamento, foram produzidos mapas de distribuição espacial, que contribui para a localização das espécies na Estação Ecológica do Jari.

Palavras-chave: Clusiaceae; 2,2-difenil-1-picrilhidrazil; Bioautografia

\section{Abstract}

Plants are an excellent source of secondary metabolites holders biological activities. These natural products have the potential to be used in different industries, such as food, agrochemistry, pharmacy, cosmetics and perfumes. Among the activities performed by the plant secondary metabolites, we can find the antioxidant activity. Compounds with these characteristics are popular among the food and pharmaceutical industries for the production of food preservatives, supplements and medications. Based on the premises above, this paper aims at evaluating the oxidant activity of Clusiaceae family, found at Jari Ecological Stations, as well as georeferencing such species within Permanent Protection Area. The species involved in this study was Garcinia macrophilla, popularly known as "bacuripari", and Clusia grandiflora, also popularly known as "cebola braba". The antioxidant assays were performed with the ethanolic extract from the roots of both plants, using the Bioauthography technique. The assay results showed that the extract from both species are active and have several antioxidant substances in its composition. Regarding the georeference process, spatial distribution maps have been generated, which helped localize the species at Jari Ecological Station.

Keywords: Clusiaceae; 2,2-diphenyl-1-picrylhydrazyl; Bioautography

\footnotetext{
Graduado em Licenciatura em Ciências Biológicas pelo Instituto Federal do Amapá; e-mail: wilsonbrun@gmail.com

Especialista em educação Profissional e Tecnológica pelo Instituto Federal do Amapá; e-mail: Iuan.silva@ifap.edu.br

II' Doutor em Química pela Universidade Federal do Pará; Professor Classe D do Instituto Federal de educação, Ciência e Tecnologia do Amapá; e-mail: haroldo.filho@ifap.edu.br
} 


\section{Introdução}

Uma das formas de se explorar racionalmente os recursos amazônicos, se dá pela utilização de espécies vegetais para estudos, no intuito de explorar potencialidades como atividades biológicas e compostos químicos, que poderão ser empregados nas indústrias farmacêutica, agroquímica, alimentícia, de cosméticos etc. Dentre os compostos obtidos de plantas de crescente interesse, encontram-se os antioxidantes, que podem dar origem à suplementos nutricionais ou produtos farmacêuticos que tem a capacidade de combater as espécies reativas de oxigênio, quando os antioxidantes endógenos são incapazes de proteger o organismo (PISOSCHI; NEGULESCO, 2011). As substâncias de fontes naturais que possuem a capacidade de bloquear o efeito danoso dos radicais livres, podem ser vitaminas, pigmentos, flavonoides, compostos fenólicos, antocianinas e alguns minerais (VASCONCELOS et al., 2014).

Uma das famílias de plantas apontadas na literatura como rica em compostos com atividade antioxidante é a Clusiaceae Lindl. (SANTA-CECÍLIA et al., 2013), que possui espécies encontradas em todas regiões do globo, com exceção da Nova Zelândia e dos polos Ártico e Antártico (FURNESS; STAFFORD, 1995). Esta família é alvo de um estudo sobre avaliação de atividade antioxidante e mapeamento das espécies detentoras de atividade encontradas na Estação Ecológica do Jari (ESEC-Jari), uma área de proteção permanente (APP) administrada pelo Instituto Chico Mendes de Biodiversidade (ICMBio), voltada à educação ambiental e pesquisas científicas, caracterizada como uma área em potencial para estudos envolvendo atividade biológica de espécies vegetais. Por pertencerem à família Clusiaceae e por serem encontradas na ESEC-Jari, Clusia grandiflora e Garcinia macrophylla, foram as duas primeiras espécies envolvidas nesse estudo. O estudo fornecerá informações sobre as propriedades biológicas das espécies e da família estudada, além de contribuir para o acervo espacial das espécies encontradas na ESEC-Jari.

Clusia grandiflora Splitg., possui flores vistosas de coloração rosada, seu fruto imaturo tem a forma semelhante a de uma cebola, por essa característica a espécie recebeu nome popular de cebola "braba". É uma planta arbórea e pode ser hemiepífita, quando seu fruto amadurece, se abre e fica com aparência de uma flor. Na medicina popular, seu xarope é muito utilizado para combater a tosse e como expectorante (BASTOS et al., 2003; COELHO-FERREIRA, 2009).

A Garcinia macrophylla Mart., é uma arvore de porte variável entre 6-20 m de altura, possui fruto, que é uma baga com polpa ácida e gosto agradável, popularmente conhecida com bacuripari ou bacuri. É nativa da Amazônia com ocorrência em sub-bosques de florestas de várzea, possui importância madeireira, alimentícia e medicinal, seu látex é utilizado para fazer gesso que alivia dores musculares e trata feridas na pele; suas cascas são utilizadas na forma de chá para aliviar dores de estômago e diarreia; a decocção de suas folhas são utilizadas para tratamento de peles rachadas de pés e para o alívio de dores (DEFILIPPS et al., 2007).

\section{Aspectos metodológicos}

\subsection{Coleta e identificação das espécies vegetais}

As espécies estudadas foram coletadas na ESEC Jari, sendo escolhidas as raízes das plantas para o estudo. A espécie Garcinia macrophylla foi coletada no dia 05 de setembro de 2017, obtendo-se $110 \mathrm{~g}$ de raízes e Clusia grandiflora no dia 11 de novembro de 2017, onde foram obtidas $978 \mathrm{~g}$ de raízes. Uma exsicata de cada espécie foi prepara e depositada no herbário do Instituto de Pesquisas Científicas e Tecnológicas do Amapá-IEPA, sob número de registro HAMAB 019131 e 019139 para G. macrophylla e C. grandiflora, respectivamente.

\subsection{Obtenção dos extratos}

As raízes coletadas foram secas à temperatura ambiente por quinze dias, trituradas em liquidificador (Astro, modelo Predileto 223 Faet) e submetidas à extração por maceração com etanol (99,5\%, Nox Lab Solutions) a temperatura ambiente por sete dias. Após a extração, o solvente foi evaporado em capela por 8 dias, resultando em 5,29 g de extrato de etanólico de G. macrophylla e 6,96 g de extrato etanólico de C. grandiflora.

\subsection{Determinação da atividade antioxidante}

A atividade antioxidante foi avaliada pelo método de bioautografia, que combina separação cromatográfica com avaliação do potencial biológico in situ a partir de artifícios químicos, trata-se de uma técnica barata e eficaz utilizada para identificar e isolar constituintes ativos em uma mistura (DEWANJEE et al., 2015). Neste trabalho, avaliou-se por bioautografia o potencial antioxidante dos extratos de G. macrophyla e $C$. grandiflora, adotando como fase móvel diclorometano/ metanol 5\% e como fase estacionária, cromatoplacas em sílica gel. Foram a aplicadas alíquotas de 25,50 e $100 \mu \mathrm{g}$ para os extratos e $500 \mathrm{ng}$ para o padrão, ácido ascórbico. Os extratos foram aplicados em diferentes concentrações para determinar qual o mais ativo, ou seja, aquele que nas menores concentrações apresentam atividade. Para a realização dos testes antioxidantes foi preparada uma solução de $0,66 \mathrm{mM}$ do radical livre 2,2-difenil-1-picrilhidrazil (DPPH) em metanol. As cromatoplacas desenvolvidas, foram borrifadas com a solução de DPPH e envolvidas com papel alumínio por 40 minutos. Em seguida as placas foram digitalizadas em fotodocumentador TLC Visualizer sob a luz branca. Vale salientar, que o DPPH na forma radicalar apresenta uma coloração roxa, ao reagir com radicais de hidrogênio (oriundos do substrato) assume a forma molecular que é amarelada. Logo, o teste consiste na avaliação da ocorrência de formação de bandas amareladas, sendo assim, sugestivo de teste positivo para a capacidade sequestradora de radical livre desse substrato (extratos e substâncias isoladas) (CHOMA; GRZELAK, 2011). 


\subsection{Georreferenciamento das espécies}

O georreferenciamento das espécies em estudo foi realizado com o auxílio de um GPS (Garmin, modelo Etrex 10). A metodologia consiste na marcação de pontos de controle de cada amostra encontrada durante o trajeto no interior da área de estudo. Foram anotadas as coordenadas $\mathrm{X}$ (Longitude) e Y (Latitude), além de numerar com placas de metal as árvores georreferenciadas. A identificação das espécies e a área de coleta das coordenadas foram realizadas com o auxílio dos funcionários da ESEC Jari. As coordenadas não foram obtidas em uma única área e sim ao longo do percurso sugerido pelos funcionários da estação ecológica.

Os dados coletados foram compilados para uma tabela eletrônica no formato CSV, para que possam assim ser inseridos no SIG (Sistema de Informações Geográficas) QuantumGis. Após a inserção dos dados no software, foram elaborados mapas temáticos mostrando a diversidade espacial das amostras vistas em campo. Os produtos cartográficos foram georreferenciados no sistema de coordenadas UTM (Universal Transversa de Mercator) e Datum WGS 1984. O trabalho de georreferenciamento das espécies G. macrophylla e C. grandiflora é o primeiro realizado para espécies vegetais dentro da ESEC Jari.

\section{Resultados e discussão}

Em relação aos ensaios antioxidantes pela técnica de bioautrografia, observa-se que ambos extratos foram ativos, essa conclusão se baseia no fato da mudança de coloração do radical DPPH onde as substâncias foram inoculadas. O radical DPPH possui uma coloração violeta, porém quando está em sua forma molecular muda para uma coloração amarelada, quando reage com alguma substância com atividade capturadora de radical livre. A atividade foi observada em todas as concentrações testadas $(25,50$ e $100 \mu \mathrm{g})$ para as duas espécies estudadas. Com base na intensidade da coloração observada nos pontos em que os extratos foram inoculados, é sugestivo que a atividade seja proporcional à concentração dos extratos, uma vez que, os extratos de maior concentração apresentaram uma coloração amarela mais intensa para as duas espécies. Observa-se ainda, que os extratos de G. macrophylla contém um número maior de compostos com características antioxidantes, pois apresentou um número de maior de bandas com coloração amarela, para a fase móvel em que a cromatoplaca foi desenvolvida. Esses resultados revelam que a técnica é eficiente para determinar se os extratos possuem compostos com atividade antioxidante.

Os resultados indicam que G. macrophylla e C. grandiflo$r a$ são produtoras de compostos com atividade capturadora de radicais livres. Tal atividade se deve à composição da família Clusiaceae, que é de xantonas, cumarinas, flavonóides e outros compostos com relatada atividade antioxidante na literatura. Acredita-se que das classes de substância presentes nos extratos, as xantonas devam ser as principais responsáveis pela atividade observada, visto que, a família Clusiaceae é uma das principais produtoras dessa classe de substâncias (FARIAS et al., 2012; SOARES, 2002; TRUEBA, 2003; RIPARDO FILHO et al., 2015).

Tendo em vista o potencial antioxidante dos extratos testados, as raízes de G. macrophylla e C. grandiflora são fontes promissoras de compostos com atividade antioxidantes e estudos relacionados ao isolamento e identificação de compostos revelaria quais os metabólitos são responsáveis pela atividade observada. Na figura 1 , observa-se a fotografia da cromatoplaca na qual foi realizado o ensaio antioxidante.

Figura 1 - Cromatoplaca utilizada no ensaio antioxidante. (1) Ácido ascórbico, 500 ng; (2) Extrato de bacurí,

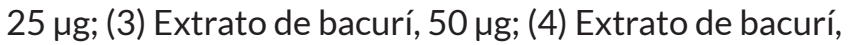

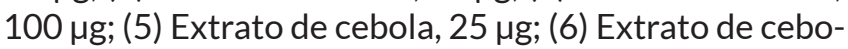
la, $50 \mu g$; (7) Extrato de cebola, $100 \mu g$.

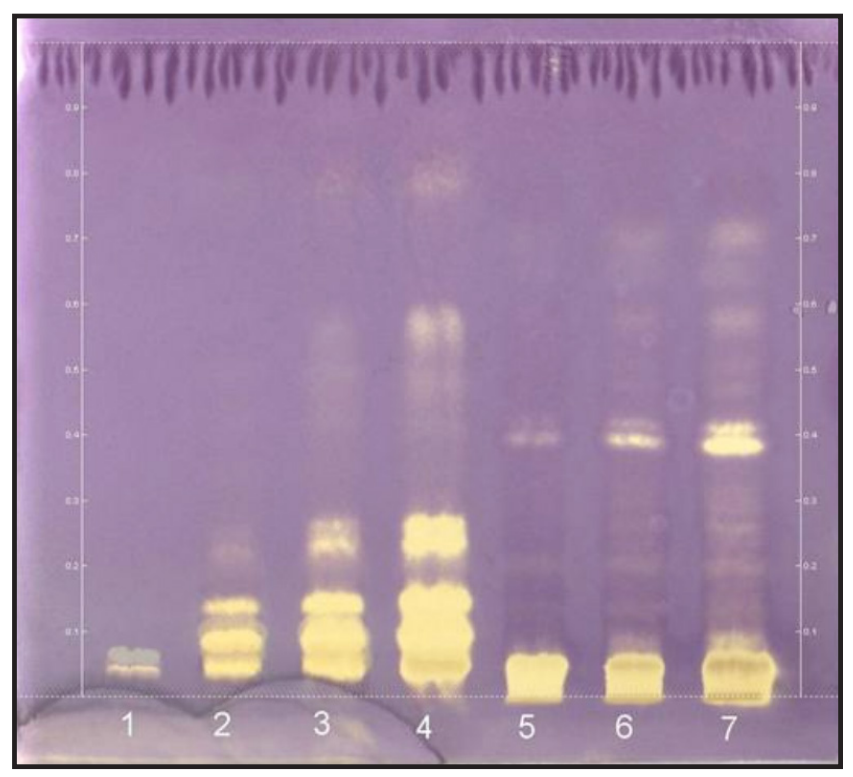

O trabalho de georreferenciamento das espécies G. macrophylla e C. grandiflora é o primeiro realizado para espécies vegetais dentro da ESEC Jari, tal levantamento permite a criação de um acervo espacial sobre a ocorrência das espécies presentes na estação ecológica. Do georreferenciamento foram obtidas 55 coordenadas das espécies estudadas, sendo 33 de $G$. macrophylla (Tabela 1) e 22 de C. grandiflora (Tabela 2).

Para G. macrophylla, a área com maior concentração de exemplares encontra-se entre os vértices de 1 a 4 , totalizando uma área de aproximadamente $12.521 \mathrm{~m}^{2}$. $\mathrm{Na}$ Tabela 3, observam-se as coordenadas dos vértices de 1 a 4 . Essa região é chamada pelos funcionários da ESEC Jari como "bacurizal”, em alusão a alta concentração de G. macrophylla. Na área são encontradas plantas jovens, de médio e de grande porte. Foram ainda observadas exemplares em outras regiões, indicando que a espécie está se propagando dentro da estação ecológica.

Durante a coleta das coordenadas, observou-se que a espécie C. grandiflora quando encontrada em vegeta- 
Tabela 1 - Coordenadas de GPS da espécie Garcinia macrophylla georreferênciada na ESEC Jari. (Y) Latitude; (X) Longitude.

\begin{tabular}{|c|c|c|c|c|c|}
\hline \multicolumn{6}{|c|}{ Garcinia macrophylla } \\
\hline Ponto & $\mathrm{Y}$ & $x$ & Ponto & Y & $x$ \\
\hline 1 & 9950451 & 294417 & 18 & 9951511 & 294209 \\
\hline 2 & 9950461 & 294415 & 19 & 9951502 & 294235 \\
\hline 3 & 9950469 & 294414 & 20 & 9951507 & 294252 \\
\hline 4 & 9950503 & 294399 & 21 & 9951501 & 294256 \\
\hline 5 & 9950887 & 294345 & 22 & 9951509 & 294257 \\
\hline 6 & 9951494 & 294169 & 23 & 9951515 & 294277 \\
\hline 7 & 9951498 & 294174 & 24 & 9951517 & 294284 \\
\hline 8 & 9951498 & 294176 & 25 & 9951520 & 294287 \\
\hline 9 & 9951499 & 294176 & 26 & 9951536 & 294299 \\
\hline 10 & 9951499 & 294189 & 27 & 9951524 & 294386 \\
\hline 11 & 9951501 & 294193 & 28 & 9951519 & 294458 \\
\hline 12 & 9951507 & 294194 & 29 & 9951509 & 294481 \\
\hline 13 & 9951509 & 294193 & 30 & 9951504 & 294485 \\
\hline 14 & 9951503 & 294191 & 31 & 9951682 & 295117 \\
\hline 15 & 9951521 & 294188 & 32 & 9951729 & 295255 \\
\hline 16 & 9951510 & 294196 & 33 & 9951752 & 295191 \\
\hline 17 & 9951510 & 294200 & & & \\
\hline
\end{tabular}

Tabela 2 - Coordenadas de GPS da espécie Clusia grandiflora georreferenciada na ESEC Jari. (Y) Latitude; (X) Longitude.

\begin{tabular}{|c|c|c|c|c|c|}
\hline \multicolumn{6}{|c|}{ Clusia grandiflora } \\
\hline Ponto & $\mathrm{Y}$ & $x$ & Ponto & $\mathrm{Y}$ & $x$ \\
\hline 1 & 9949491 & 296633 & 12 & 9949533 & 296567 \\
\hline 2 & 9949531 & 296583 & 13 & 9949522 & 296539 \\
\hline 3 & 9949534 & 296583 & 14 & 9949446 & 296560 \\
\hline 4 & 9949532 & 296584 & 15 & 9949439 & 296547 \\
\hline 5 & 9949530 & 296586 & 16 & 9949497 & 296615 \\
\hline 6 & 9949533 & 296575 & 17 & 9949435 & 296213 \\
\hline 7 & 9949531 & 296573 & 18 & 9949429 & 296190 \\
\hline 8 & 9949534 & 296569 & 19 & 9949424 & 296203 \\
\hline 9 & 9949533 & 296568 & 20 & 9949403 & 296212 \\
\hline 10 & 9949534 & 296570 & 21 & 9950265 & 294491 \\
\hline 11 & 9949533 & 296570 & 22 & 9951751 & 295268 \\
\hline
\end{tabular}


ção mais baixa, apresenta hábito terrestre, porém, em regiões onde a mata é mais alta, a espécie localiza-se na copa das árvores, apresentando hábitos hemiepífitas. O hábito hemiepífita indica ser uma adaptação da espécie para captação da luz solar.

A maioria das coordenadas de C. grandiflora foram obtidas de espécies terrestres, visto que, as encontradas na copa das árvores são de difícil visualização e consequentemente difícil identificação. As coordenadas dos exemplares de C. grandiflora foram obtidos em sua maioria próximas a sede do alojamento da ESEC Jari, onde a vegetação é mais baixa. As coordenadas desses exemplares foram coletadas entre os vértices de 5 a 8 , em uma área que corresponde $6.474 \mathrm{~m}^{2}$. As coordenadas dos pontos de 5 a 8 , estão apresentadas na Tabela 3. Ao longo do percurso foram encontrados outros 6 exemplares da espécie e obtidas suas coordenadas, porém todas elas de hábitos hemiepífitas.

A partir do georreferenciamento foram gerados dois mapas, o primeiro que mostra uma visão geral da estação ecológica e a região onde foram coletadas as coordenadas (Figura 2) e o segundo mostra os pontos marcados ao longo do trajeto percorrido (Figura 3). Os mapas fornecem a real localização de onde essas

Tabela 3 - Tabela dos vértices das áreas de maior concentração das espécies estudadas.

(Y) Latitude; (X) Longitude.

\begin{tabular}{|c|c|c|}
\hline \multicolumn{3}{|c|}{ Garcinia macrophylla } \\
\hline Vértice & $x$ & Y \\
\hline 1 & 294164.12 & 9951538.29 \\
\hline 2 & 294300.06 & 9951538.29 \\
\hline 3 & 294164.12 & 9951491.32 \\
\hline 4 & 294299.74 & 9951491.32 \\
\hline \multicolumn{3}{|c|}{ Clusia grandiflora } \\
\hline Vértice & $x$ & $\mathrm{Y}$ \\
\hline 5 & 296529.19 & 9949538.73 \\
\hline 6 & 296529.19 & 9949434.52 \\
\hline 7 & 296648.33 & 9949434.52 \\
\hline 8 & 296648.33 & 9949537.8 \\
\hline
\end{tabular}

Figura 2 - Mapa com a visão geral da ESEC - Jari e da trilha durante o georreferenciamento das espécies estudadas.

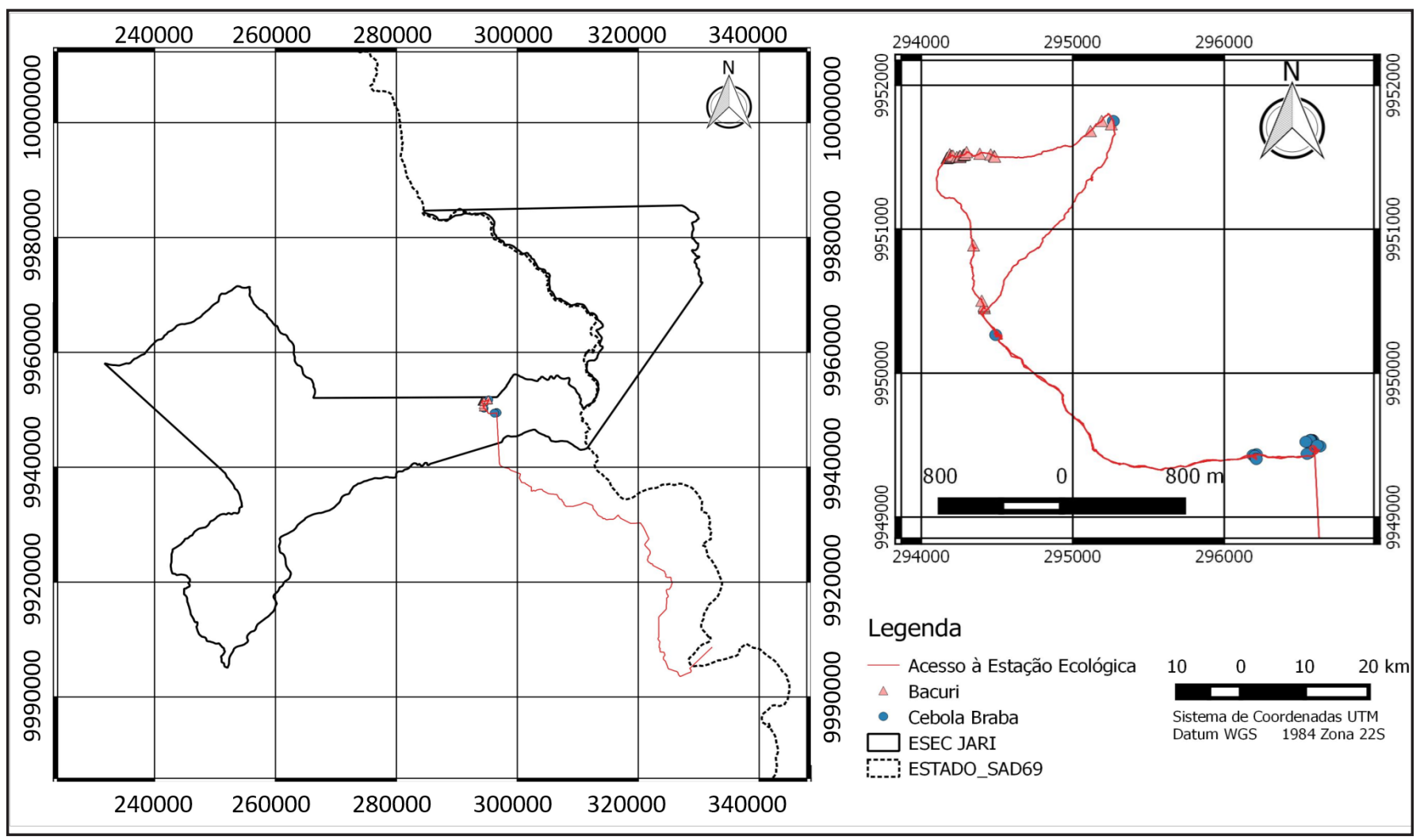


Figura 3 - Mapa das regiões de maior ocorrência das espécies estudas ao longo do trecho percorrido na ESEC Jari.

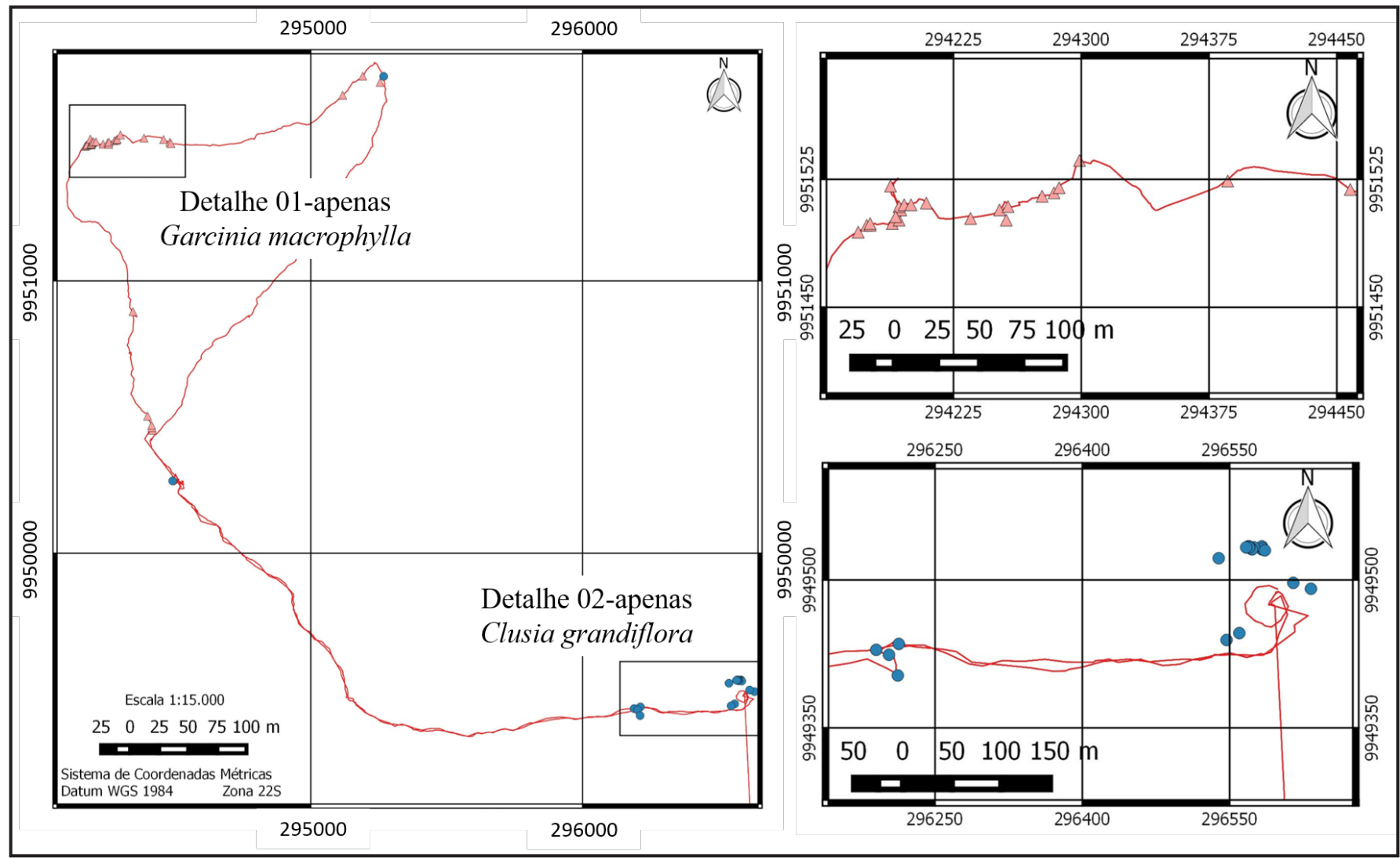

espécies ocorrem dentro da reserva e as regiões de maior concentração, contribuindo com acervo espacial da ESEC Jari, além de servir de suporte para futuras pesquisas envolvendo as espécies G. macrophylla e $C$. grandiflora.

\section{Conclusões}

O trabalho realizado mostrou que a ESEC Jari possui uma excelente área para realização de estudo com espécies vegetais, nela são encontradas espécies da família Clusiaceae, dentre elas as espécies G. macrophylla e C. grandiflora. O georreferenciamento das espécies estudadas foi o primeiro realizado na ESEC, fornecendo dados espaciais sobre a localização de G. macrophylla e C. grandiflora, que pode servir de suporte e estímulo para futuros trabalhos e contribui para o acervo espacial de espécies vegetais da estação ecológica. As espécies G. macrophylla e C. grandiflora apresentaram atividade antioxidante, comprovando que suas raízes podem ser uma boa fonte de compostos com tais características. Por conta dos resultados obtidos, estudos mais aprofundados envolvendo isolamento e identificação, serão importantes para a descoberta de quais as substâncias são as responsáveis pela atividade capturadora de radicais livres observada. Os resultados estão de acordo com dados obtidos na literatura para a família Clusiaceae, por serem a classe de substâncias predominante na família e por possuírem relatada atividade antioxidante, as xantonas, indicam ser as responsáveis pela atividade observada. O trabalho realizado fornece informações sobre a flora da ESEC Jari e amplia o conhecimento sobre a família Clusiaceae.

\section{Referências}

BASTOS MNC, COSTA DCT, SANTOS JUM. Vegetação de restinga: aspectos botânicos e uso medicinal. Belém: Museu Paraense Emílio Goeldi (Projeto RENAS/ IDRC/ CRDI); 2003.

CHOMA IM, GRZELAK EM. Bioautography detection in thin-layer chromatography. J. Chromatogr. A. 2011;1218(19):2684-2691.

COELHO-FERREIRA M. Medicinal, knowledge and plant utilization in an Amazonian costal community of Marudá, Pará state (Brazil). J. Ethnopharmacol. 2009;126:159-175.

DEFILIPPS RA, MAINA SL, CREPI J. Medicinal plants of the Guianas (Guyana, Surinam, French Guiana). Washington, DC: Smithsonian Institution; 2004.

DEWANJEEA S, GANGOPADHYAYB M, BHATTACHARYAA N, KHANRAA R, DUAA TK. Bioautography and its scope in the field of natural product chemistry. J. Pharmaceut. Anal. 2015;5(2):75-84.

FURNESS SH, STAFFORD PJ. Polygalaceae. Ver. Paleobot. Palynol. 1995;88:61-82. 
FARIAS JA, FERRO JN, SILVA JP, AGRA IK, OLIVEIRA FM, CANDEA AL, CONTE FP, FERRARIS FK, HENRIQUES M, CONSERVA LM, BARRETO E. Modulation of inflammatory processes by leaves extract from Clusia nemorosa both in vitro and in vivo animal models. Inflammation. 2012;35:764-771.

PISOSCHI AM, NEGULESCU GP. Methods for Total Antioxidant Activity Determination. Biochem. Anal.

Biochem. 2011;1(1):1-10.

RIPARDO FILHO HS, PACHECO LC, ANDRADE ES, CORREA MJC, ARAÚJO RNM, GUILHON GMSP, SILVA JKR, SANTOS LS. Xanthones from the Roots of Moutabea guianensis Aubl. Molecules, 2015;20:127-134.

SANTA-CECÍLIA FV, ABREU FA, DA SILVA MA, DE CASTRO EM, DOS SANTOS MH. Estudo farmacobotânico das folhas de Garcinia brasiliensis Mart. (Clusiaceae). Rev. Bras. Plantas. Med. 2013;15(3):397-404.

SOARES SE. Ácidos fenólicos como antioxidantes. Rev. Nutr. 2002;15:71-81.

TRUEBA GB. Los flavonoides: antioxidantes e prooxidantes. Rev. Cubana Invest. Bioméd. 2003;22:48-57.

VASCONCELOS TB, CARDOSO ARNR, JOSINO JB, MACENA RHM, BASTOS VPD. Radicais Livres e Antioxidantes: Proteção ou Perigo? UNOPAR Cient Ciênc. Biol. Saúde. 2014;16(3):213-219. 